\title{
Erratum
}

\section{The convergence of the British and French models of capitalism}

\author{
Daniel Simonet
}

French Politics (2014) 12, 192. doi:10.1057/fp.2014.10

Correction to: French Politics (2014) 12, 1-21. doi: 10.1057/fp.2014.5

The author corrections to the abstract section were omitted from the published version. The correct abstract is printed below:

\begin{abstract}
Despite political support and reiterated calls for re-industrialization, the German model (defined as a strong industry backed by the banking sector; greater cooperation between trade unions, the government and corporate boards; an exportdriven economy) has remained unachievable in France. The industrial sector and exports have been receding since the 1970s; industrial relations have deteriorated and the 'National champions' policy (that is, picking winners, for example, Airbus, or creating them via mergers, subsidizing large-scale pivotal industries, for example, IT Plan of 1968, coal and steel industries) was abandoned in the 1980s. Did that vacuum let the British model slowly take root in France? Are France and the United Kingdom heading toward greater convergence, or do elements of differentiation remain? This article argues that despite some changes to a more liberal political economy, the adoption of British-modelled 'active' labor policies, and a shift to international and financial capitalism in France, the British and French models are not to be seen as convergent. The business oligarchy and family capitalism remain stronger in France than in the United Kingdom. The current crisis help highlight persistent differences.
\end{abstract}

We would like apologise for any inconvenience this error has caused. 